\title{
Quality parameters for the e-learning Omega system
}

\author{
Ksenija Klasnić \\ Student at the Faculty of Humanities and Social Sciences, \\ Ivana Lučića 3, 10000 Zagreb, Croatia \\ kklasnic11@yahoo.com \\ Sanja Seljan, Ph.D. \\ Faculty of Humanities and Social Sciences, Department of Information Sciences \\ Ivana Lučića 3, 10000 Zagreb, Croatia, tel/fax: +38516002350 \\ sanja.seljan@ffzg.hr \\ Hrvoje Stančić, Ph.D. \\ Faculty of Humanities and Social Sciences, Department of Information Sciences \\ Ivana Lučića 3, 10000 Zagreb, Croatia, tel/fax: +38516002350 \\ hrvoje.stancic@zg.t-com.hr
}

\begin{abstract}
Learning and teaching are considered to be the main activities in higher education. The environment in which these activities take place is rapidly changing and it is getting more and more oriented towards teaching with the help of the new technologies, namely e-learning system, relying not only on technical skills but also on motivation and contextualisation.

In the paper, different views towards the quality of e-learning have been presented, and the research regarding the quality of the e-learning Omega system (Moodle) conducted at the Faculty of Humanities and Social Sciences, University of Zagreb presented in relation to different European policies.
\end{abstract}

Key words: e-learning, quality measurement, Croatia, European context.

As e-learning has become an increasingly important issue in educational systems in the last several years a considerable number of standards, guidelines and frameworks have been published relating to better efficiency and quality improvement of the e-learning. While early initiatives were concentrated on the functional understanding and technical skills of ICT use, nowadays they take more into consideration motivation, satisfaction and contextualisation which are reflected in the quality of e-learning.

According to concrete future objectives of the European legislation, ref. [2] the European Commission and Council have defined several basic objectives in accordance with the Lisbon strategy, which are:

1. To improve quality of education and training systems, enabling to teachers to acquire basic skills particularly with relation to ICT, access to Internet and increase of investment in human resources;

2. Making access to learning easier including formal and non-formal education;

3. Opening education and training to the world through mobility, opening of systems, language teaching.

According to communication from the Commissions, ref. [3] the policy of investment in education and training take into account ICT development and reforms concerning curricula, quality and recognition.

\section{Introduction}

The quality, being quite complex to define and asking for changes in organisation, type of education, pedagogical adaptation and new skills, depends on the purpose of its use, simplicity, cost effectiveness, coherence of design, etc. 
Although there are numerous parameters relating to quality mark, the quality process has been generally described as a relation between staff and students characterised by Dialogue, Involvement, Support and Control (DISC), as in Stephenson [2005].

Furthermore, the quality is described through different perspectives:

- broader perspective including ICT qualifications, online academic management, self-inscription, personalisation, virtual campuses, e-learning experience, participation in shared campuses or

- more fundamental approach covering learning effectiveness, student and faculty satisfaction, cost effectiveness and access

- at operational level is oriented more to good practice and conventional pedagogical model including encouragement of students, cooperation, active learning and feedback, task managing, communication and respecting talent

- at pedagogical level the quality would include motivation, program flexibility, goal orientation, motivation, teacher's role, learner control, user's activities, cooperative learning, etc.

- the longer term perspective includes return on investment, specially when applying ICT programmes where evaluation could be performed at reaction level, learning (changing of attitudes), behaviour and results.

According Stephenson [2005] the quality in other reviews includes parameters as:

- the impact of ICT,

- wider purpose of university education,

- quality as coherence of understanding and practice

pointing out that all students should take responsibility for their further learning after graduation.

EFQUEL (European Foundation for Quality in eLearning) [2007] indicates a set of starting principles:

- integration of European quality mark,

- innovation in transformation processes,

- transparency of the process and of the results,
- modularity of the quality mark,

- efficiency for avoiding overload of work,

- relevance of the working experience,

- context sensitivity for good practice,

- scalability from the pilot model to full implementation,

- adaptability to future needs and conditions of the institution.

Reactions to the use of the e-learning system are often very opposite, depending on the purpose of the use, context, user's attitudes, etc.

According to the findings in Bizmedia [2002] $61 \%$ of all respondents rated the quality of the e-learning system negatively, $6 \%$ as excellent or very good. According Bizmedia [2002] there are four most important criteria for quality evaluation:

- to function technically without problems for all users,

- to have clear explicit pedagogical principles appropriate for type of the learning, its needs and context,

- subject content should be state of the art maintained up to date, and

- the content should have high level of interactivity.

On the other side, it is seen positively, as stated in Mc McCullough and Aimard [2006] where the accent is given to the human dimension, i.e. pedagogical approach. Respondents also said that e-learning requires skills like critical thinking, self-study and learning skills. As the quality refers to user's views on the e-learning, in the paper a survey has been presented concluding with the importance to define:

- who are respondents,

- what is e-learning according to teachers and learners,

- how is e-learning rated and what is the future of e-learning.

Furthermore, the respondents have indicated different types of skills developed when using e-learning training:

- pedagogical skills;

- learning skills (participation in on-line collaborative groups and self-study 
skills), both perceived as the most important ones;

- cognitive skills (dealing with great amount of information, articulation of knowledge);

- technical skill relating to the use of authoring tools, publishing and editing of multimedia content;

- organisational skills relating to project management skills and information/content organisation skills.

\section{E-learning system Omega (Moodle)}

A the Faculty of Humanities and Social Sciences, University of Zagreb an open-source course management system (CMS) MOODLE $^{1}$ has been used since 2000/2001, started from the project Organization of Information and Knowledge in the Electronic Learning Environment http://infoz.ffzg.hr/ oizeoo.

As the Faculty functions almost as a small university, constituted out of 23 Departments, 33 undergraduate programmes, and considerable number of postgraduate programs, with around 6,100 students of whom the majority study at two departments i.e. has two majors, a constant problem of time and space for lectures and tutorials is present. Besides organizational and infrastructural constraints, need for the creation of new and robust teaching and learning environments using ICT was perceived as a prerequisite for the achievement of future educational reforms. Therefore, Moodle's interface was translated, customized and implemented for the academic year 2004./2005 under the name OMEGA. The fact that Moodle is a free, easy-to-use system (i.e. everyone with basic computer literacy can easily use it) with simple and understandable interface was the main reason for the implementation. At the moment Omega has been used by 20 departments, containing about 200 courses and used by 2,200 students.

${ }^{1}$ The word Moodle was originally an acronym for Modular Object-Oriented Dynamic Learning Environment.
As Omega e-learning system is used by a considerable number of teachers and students, it is important to determine the degree of Omega's implementation in the educational system of Faculty and also the quality of this implementation.

One of the indicators of efficacy and quality of the implementation and integration of elearning systems in the educational system is taken to be students' satisfaction with the system and its use.

Therefore, a survey was conducted at the Faculty of Humanities and Social Sciences to determine students' attitudes and satisfaction with the use of Omega. Students' attitudes have been defined as the dependent variable.

\section{Quality parameters}

Taking into consideration previous classifications and frameworks, the attitudes were classified into four main groups:

- attitudes about the need of the greater integration of Omega in educational system,

- attitudes about the possibilities of enhancing the quality of teaching and learning using Omega,

- attitudes about the quantity, and

- attitudes about the quality of the use of Omega in education.

\section{Research - methods and sample}

To examine these attitudes we conducted a study using the survey on the congruent quot sample of the Faculty of Humanities and Social Sciences students $(\mathrm{N}=148)$. The study was conducted in May 2007. The survey consisted of 32 instruments which were covering the relevant aspects for analyzing this subject.

Sample description: there were $74 \%$ female and $26 \%$ male examinees, all years of study were equally represented in the sample, the most students were from the Department of English (34\%), Sociology (29\%) and Information sciences $(20 \%)$. Also, the greatest 
number of students were from Zagreb (39\%) than Dalmatian region and the islands (11\%) and from Zagorje (10\%). The greatest number of students estimated their economical status as average (60\%). There is a bit more of those who estimated their economical status better $(25 \%)$ then the ones who estimated their economical status worse than average $(15 \%)$. The greatest number of students has average grades between 4.01 and $4.50(34 \%)$ which is, by our remark, very high grades average for University grades. They are followed by the ones with the average between 3.51 and $4.00(25 \%)$ and then by the ones with the highest average, that is higher than 4.51 (21\%).

\section{Interpretation of the results}

The research showed that the majority of students have generally positive attitudes towards Omega. Students mostly believe that Omega is:

- a useful contribution to the educational system (88\%),

- that it helps distribution of class materials $(88 \%)$, and

- raises the degree of students' information literacy $(77 \%)$.

They consider Omega to be practical because by using it they can manage some tasks from their home instead of having to go to the Faculty (78\%).

Moreover, the majority of students don't think that the use of Omega is too complicated $(85 \%)$ nor that it requires too much computer knowledge.

They also don't think that Omega should be used only by students from the Department of Information Sciences (90\%) which is a very important finding because it indicates the fact that the students are aware that technology, and information technology especially, has become an everyday requirement for experts of all professional orientations. When speaking about Omega satisfaction in general and satisfaction with its options, students are on an average:
- the most satisfied with the organization of contents on Omega (on the scale from 0 to $5, \overline{\mathrm{X}}=3.69$ ),

- followed by the average satisfaction with the possible ways of communication between students and teachers via Omega ( $\overline{\mathrm{X}}=3.47$ )

- and visual appearance of the Omega's interface $(\overline{\mathrm{X}}=3.42)$.

The minimal average satisfaction is the average regarding the satisfaction with the updates of the class materials on Omega $(\overline{\mathrm{X}}=3.39)$.

Naturally, how often will the class materials be updated depends exclusively on the teachers who use Omega.

Therefore we could conclude that the students are satisfied with the technical solutions of Omega, but not with the way their teachers use it.

This hypothesis is also supported by data regarding the frequency of the use of various Omega's options. The most frequently used options by students are:

- downloading the class materials (on the scale from 1 to $5, \overline{\mathrm{X}}=3.21$ ),

- forum searches $(\bar{X}=2.73)$,

- $\quad$ and homework uploads ( $\bar{X}=2.55$ ).

The least frequently used options are:

- $\operatorname{blog}(\bar{X}=1.07)$,

- $\quad$ chat $(\bar{X}=1.27)$, and

- forum $(\bar{X}=1.55)$ (the majority of students never used those options).

The options for which the greatest number of students doesn't even know that they exist are:

- knowledge testing (6.1\%),

- blog $(5.5 \%)$, and

- calendar (5.4\%).

From these results we can conclude that regardless of the numerous Omega's options, the majority of them are never or rarely used by students, and some of the options are for them completely unknown.

Students also estimate that for teachers who have courses on Omega the least frequently used options are: 
- blog (on the scale from 1 to $5, \bar{X}=1.18$ ),

- $\operatorname{chat}(\overline{\mathrm{X}}=1.18)$, and

- avatar changing $(\bar{X}=1.19)$ (most of the teachers never used those options).

The teachers' most frequently used options are:

- upload of class materials ( $\bar{X}=4.04)$,

- calendar input $(\bar{X}=3.12)$, and

- demands for homework uploading $(\bar{X}=3.00)$.

As we can see, the students' least frequently used options are approximately corresponding with the teachers' least frequently used options and the same pattern can be applied on the most frequently used options. This pattern indicates that teachers should be much better educated and informed with all of the options and possibilities that Omega offers, so that they could pass on their knowledge to their students. If the teachers started using other Omega's options and possibilities, students would be obliged to use the same options. In this way the use of Omega would be richer and the students would get higher-quality online education.

As regards to the use of other information technologies in educational purposes, students have estimated that teachers most frequently use online announcements regarding the classes (on the scale from 1 to 5, $\overline{\mathrm{X}}=3.87$ ) by which they have probably at the same time thought of Omega and department's online notice boards.

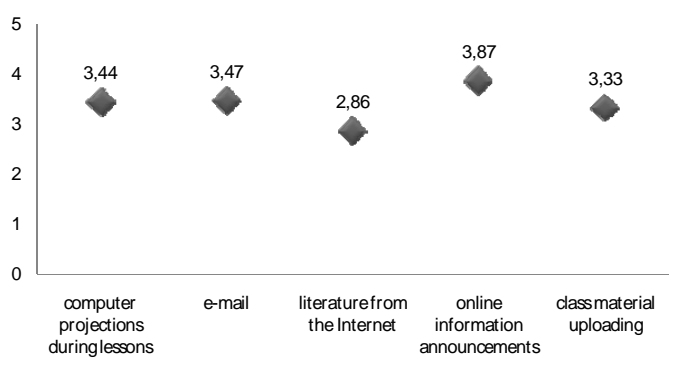

Chart 1 The use of IT in educational purposes (average score on the scale from 1-never to 5very often)
Most students stated that their teachers often announce information on the Internet (41\%). Online information announcements $(\bar{X}=3.87)$ are followed by the use of e-mail $(\bar{X}=3.47)$, computer projections during lessons $(\bar{X}=3.44)$ and class material uploading $(\bar{X}=3.33)$, and the thing that teachers use the least often is literature from the Internet ( $\overline{\mathrm{X}}=2.86$ ).

On the question about the frequency of Omega use on their departments most students answered that Omega is used rarely $(47 \%)$ and some over one fourth estimated that it is used very often. Almost $11 \%$ of the students never used Omega.

When asked to evaluate the number of teachers that use Omega, almost half of the students (49\%) stated that Omega is used by less then one fourth of their teachers.

There is a similar situation with the number of courses enrolled on Omega: over half of the students $(51 \%)$ stated that less then one fourth of the courses that they have attended or are currently attending are on Omega.

We also wanted to know how well and how often students use computers and, also, their judgments on the degree of their teachers' computer skills. Students graded their own computer skills with the average grade 3.9.

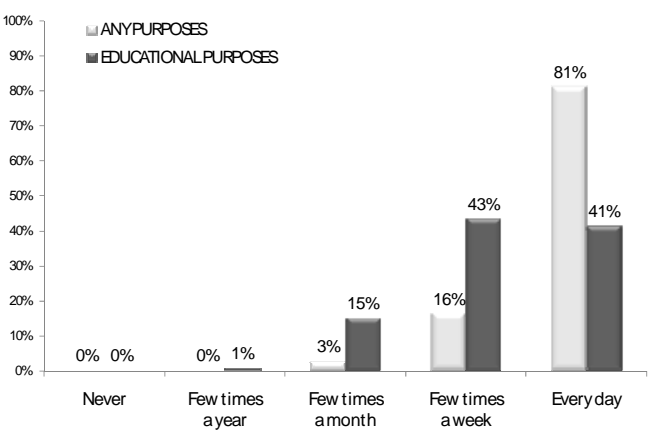

Chart 2 Frequency of the use of the computers

Over $80 \%$ of students use computers every day and over $40 \%$ of them use computers every day in educational purposes. It is sig- 
nificant that no one answered that he/she have never used computer in educational purposes and less than $1 \%$ uses computers in educational purposes very rarely, that is, few times a year. Although most of the students are satisfied with their own computer knowledge and skills, only one fourth of them don't consider the need for improvement of their skills. It seems that students want to bring their own computer knowledge and skills up to a maximum level.

Collected data indicate a great prevalence of students' computer use and a powerful desire for improvement of their own information literacy which can serve as a foundation for a greater future integration of Omega in the educational system. Students use computers daily so why shouldn't Omega become one of their frequently visited web pages?

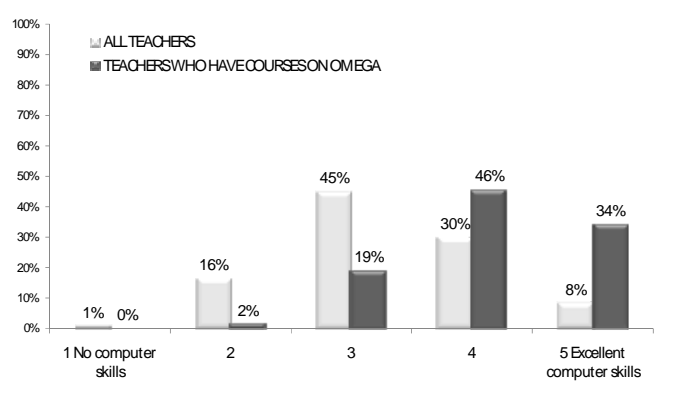

Chart 3 The degree of teachers' computer skills

When asked to evaluate their teachers' computer skills on a scale from 1 to $5(1=$ no computer skills; $5=$ excellent computer skills), students gave their teachers an average grade 3.29 while teachers who have courses on Omega got an average grade 4.12. These evaluations tell us that teachers who have courses on Omega also have better computer skills then generally all teachers together. We believe that the degree of teachers' computer skills and a basic knowledge about information technologies are the basic precondition for a teachers' decision to use Omega. We also believe that it is not only necessary to work on an increase of students' information literacy but the pri- mary concern should be an increase of teachers' information literacy. That is the prime and unavoidable step towards the integration of any information technology in an educational system.

Concerning the students' motivation for learning and studying we determined that the majority of students (88\%) decided to attend university because that is what they (have always) wanted to do. One of the students' main motives for learning and studying is the assurance of a better and financially secured future and the desire for acquisition of new knowledge as well. We can conclude that the students' basic motivation for learning and studying is a specific combination of extrinsic and intrinsic motivational factors.

\section{Dependent variables - students' at- titudes}

As dependent variables in our research we defined students' attitudes towards the need of a greater integration of Omega in the educational system, attitudes towards the possibilities of educational quality enhancement using Omega and students' satisfaction with the quality and the quantity of the use of Omega.

The data have shown that the majority of students agree with the idea of a need for a greater integration of Omega in the educational system. Most students think that all of the teachers should be introduced with Omega's possibilities and the way of its use $(83 \%)$ and that Omega should be used on all departments of their faculty (73\%). Analyses have shown that male students are more apt to these attitudes then female ${ }^{2}$ and that students from the 1st year are also more apt to these attitudes than students from all other years of study ${ }^{3}$. We also determined that the greater preference of positive attitudes towards Omega imply a greater need for

\footnotetext{
${ }^{2}$ t-test; $\mathrm{t}=2.922, \mathrm{p}=0.004$

${ }^{3}$ Analysis of variance; $F=4.012, p=0.009$
} 
Omega's integration in educational system. ${ }^{4}$ Moreover, the same need is more typical for those students who estimate that their teachers more often use information technologies in educational purposes ${ }^{5}$, students who have better computer skills ${ }^{6}$, who use computers more often (whether that use is in educational $^{7}$ or any other purposes ${ }^{8}$ ) and, finally, students who are more satisfied with their own computer skills and knowledge ${ }^{9}$.

Students' attitudes towards the possibilities of educational quality enhancement using Omega are mostly positive. The majority of students agree with the statements that it is more practical to download class materials from Omega than to write down during lessons $(75 \%)$ and that Omega compels teachers to be more systematic which helps students greatly $(68 \%)$. Very small percentage of students agrees with the statement that students would be preoccupied with commitments if all of the courses were on Omega (19\%). This means that all other students, who disagree with this statement, do not consider Omega as a burden but, contrary, as assistance and a source of a greater educational quality.

Students who have greater affinity towards the opinion that the use of Omega enhances educational quality are those who have more positive general attitudes towards Omega ${ }^{10}$, those who are more satisfied with Omega and its options ${ }^{11}$, those who estimate that their teachers more often use information technologies in educational purposes ${ }^{12}$, those who more often use computers in educational purposes ${ }^{13}$ and those who are more

\footnotetext{
${ }^{4}$ Pearson's correlation; $\mathrm{r}=0.728, \mathrm{p}<0.001$; $\mathrm{r}=0.486, \mathrm{p}<0.001$

${ }^{5}$ Pearson's correlation; $r=0.315, p=0.005$

${ }^{6}$ Pearson's correlation; $\mathrm{r}=0.362, \mathrm{p}<0.001$

${ }^{7}$ Pearson's correlation; $\mathrm{r}=0.367, \mathrm{p}<0.001$

${ }^{8}$ Pearson's correlation; $\mathrm{r}=0.317, \mathrm{p}<0.001$

${ }^{9}$ Pearson's correlation; $r=0.307, p<0.001$

${ }^{10}$ Pearson's correlation; $\mathrm{r}=0.678, \mathrm{p}<0.001$; $\mathrm{r}=0.444, \mathrm{p}<0.001$

${ }^{11}$ Pearson's correlation; $r=0.199, p=0.023$

12 Pearson's correlation; $\mathrm{r}=0.297, \mathrm{p}<0.001$

${ }^{13}$ Pearson's correlation; $r=0.277, \mathrm{p}<0.001$
}

satisfied with their own computer skills and knowledge ${ }^{14}$.

Students are generally more satisfied with the quality (on the scale form 1 to 5 $\bar{X}=3.28)$ than with the quantity $(\bar{X}=2.69)$ of the use of Omega.

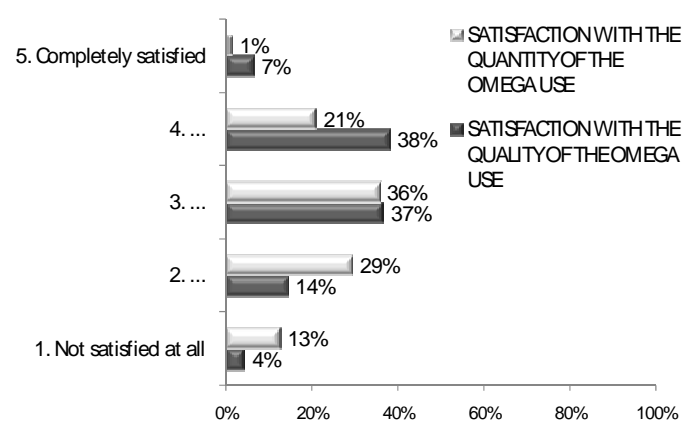

Chart 4 Satisfaction with the quantity and the quality of the use of Omega

Over $40 \%$ of students are dissatisfied with the quantity of Omega use on their faculty and they think that Omega should be used more often, while $22 \%$ of the students are satisfied with the current quantity of Omega use. Opinions about the quality of Omega use are, as we said, more positive: almost $45 \%$ of students are satisfied, while less than $20 \%$ of them are dissatisfied with the quality of Omega use on their faculty.

We determined that male students are more satisfied with the quantity of Omega use then female ${ }^{15}$. There is also a difference in average satisfaction with the quantity of Omega use among students on different years of study: students from the 1st year are more satisfied than students from all other years ${ }^{16}$. Students of the 1 st year are studying by the program based on the Bologna Declaration and they are the 2nd generation studying by the new university program. We assume that the new program has contributed to a teachers' greater use of Omega and therewith also affected on students' attitudes. It means that because the students

\footnotetext{
${ }^{14}$ Pearson's correlation; $\mathrm{r}=0.164, \mathrm{p}=0.048$

${ }^{15} \mathrm{t}$-test; $\mathrm{t}=2.074, \mathrm{p}=0.040$

${ }^{16}$ Analysis of variance; $F=8.967, p<0.001$
} 
have been given the opportunity to use Omega more often, they have also been given an opportunity for a better insight of its options and they have recognized its potential and advantages.

There is also a connection between students' satisfaction with the quantity of Omega use and the place of residence during schooling: the smallest their residence place during schooling was, the greater is their satisfaction with the quantity of Omega use ${ }^{17}$. On the contrary, students from a larger residence places are less satisfied and more apt to an opinion that Omega is not being used enough. We also determined that the students who are more satisfied with the quantity of the use of Omega are those who are generally more satisfied with Omega and its options $^{18}$, who estimate that their teachers more often use information technologies in educational purposes ${ }^{19}$ and those who estimate that their teachers have better computer skills $^{20}$.

Satisfaction with the quality of the use of Omega is connected with the following variables: students from the 1st year are more satisfied than students from all other years of study ${ }^{21}$ which also applies to students with higher grade average ${ }^{22}$. There is also a connection between the first factor ${ }^{23}$, that is, the first group of attitudes towards Omega (Omega is a necessary addition to university education, it is not burdening the students, it should be used on all departments, it is not

\footnotetext{
${ }^{17}$ Pearson's correlation; $\mathrm{r}=-0.189, \mathrm{p}=0.024$

${ }^{18}$ Pearson's correlation; $r=0.229, \mathrm{p}=0.009$

${ }^{19}$ Pearson's correlation; $\mathrm{r}=0.414, \mathrm{p}<0.001$

${ }^{20}$ Pearson's correlation; $\mathrm{r}=0.333, \mathrm{p}<0.001$

${ }^{21}$ Analysis of variance; $\mathrm{F}=5.563, \mathrm{p}=0.001$

22 Pearson's correlation; $r=0.192, p=0.024$

${ }^{23} \mathrm{We}$ conducted a factor analysis on statements that were used to measure attitudes towards Omega. The analysis generated 3 statistically significant factors, from which 2 were consistent enough to include them in further analysis like this one.
}

too demanding to use etc.) and the satisfaction with the quality of its use $\mathrm{e}^{24}$.

Greater satisfaction with the quality of Omega use is also connected with the students who are generally more satisfied with Omega and its options ${ }^{25}$, those who estimate that their teachers more often use information technologies in educational purposes ${ }^{26}$, those who have better computer skills ${ }^{27}$ and those who estimate that the teachers who have courses on Omega have better computer skills ${ }^{28}$.

\section{Conclusion}

All the above mentioned results indicate the following conclusion: positive attitudes towards Omega, perceiving its qualities and the possibilities of positive changes by its use, are typical for those students who were, thanks to their information literate teachers and their own information literacy, given the opportunity for a better familiarization with Omega.

It is our opinion that the quality education, and specially education and educational engagements using Omega, are not possible without a quality educated and prepared teachers. If we review the situation in the context of a concept of technological pedagogical content knowledge, which implies that the modern quality teacher is the only one that understands and successfully uses these three knowledge components, we realize that the component referring to the technology and the use of technology in education is the key problem in the process of integration of Omega in the educational system on Zagreb's Faculty of Humanities and Social Sciences.

It seems that teachers are still having "problems" with unavoidable characteristic of a quality teacher, which is reflected in students' attitudes and satisfaction. Still, the

\footnotetext{
${ }^{24}$ Pearson's correlation; $\mathrm{r}=0.259, \mathrm{p}=0.003$

${ }^{25}$ Pearson's correlation; $r=0.450, p<0.001$

${ }^{26}$ Pearson's correlation; $\mathrm{r}=0.445, \mathrm{p}<0.001$

${ }^{27}$ Pearson's correlation; $r=0.188, \mathrm{p}=0.028$

${ }^{28}$ Pearson's correlation; $\mathrm{r}=0.348, \mathrm{p}<0.001$
} 
good news is that the situation, as it seems, is moving into the right direction because the students from the lower study years are more satisfied with Omega use. to this fact we should probably congratulate the new "Bologna" university educational system.

At the end we would like to notice that this research didn't involve all aspects of analysed problem partially because of the practical limitations, but mostly because of the complexity of the research subject. Anyhow, researches on this thematic should be conducted regularly with a view to a better understanding of a situation considering the quality of Omega's integration in educational system and students' satisfaction with the way of its use. The results of such researches could serve as a foundation and a guideline in undertaking of appropriate steps with the objective of enhancement of universal education quality.

According to the presented results the future of e-learning is seen in blended learning but not only in formal setting, but also in the life long learning. It demand not only pure technical skills, but also social dimension (motivation, contextualisation, learners' needs, recognition) in order to develop different type of skills and knowledge and to be quality oriented.

The presented results are the outcome of the research project "Information Technology in Computer-Assisted Translation of Croatian and in e-Language Learning" (130-13006460909) undertaken with the support of the Ministry of Science, Education and Sport of the Republic of Croatia.

\section{References:}

(1)Bonk, Curtis J. Current Myths and Future Trends in Online Teaching and Learning, 2006. http://www.courseshare.com/cjb onk/myth trend.html (3.10.2007)

(2) Europa: Summaries of legislation: Education and Training: General framework. Concrete future objectives of education systems, 2001. http://europa.eu/scadplus/ leg/en/cha/c11049.htm (13.2.2008)

(3) Europa: Summaries of legislation: Education and Training: General framework. Investing efficiently in education and training, 2003. http://europa.eu/scadplus/ leg/en/cha/c11066.htm (13.2.2008)

(4) European Foundation for Quality in eLearning, EFQUEL. Quality Assurance and Accreditation for European eLearning: the Case for a European Quality Mark Initiative, Green Paper No. 4. Brussels, 2007.

(5) Kyong-Jee, Kim; Curtis, Bonk J. The Future of Online Teaching and Learning in Higher Education. EDUCAUSE Quarterly Magazine, Volume 29, No. 4, 2006.

(6) Kyong-Jee, Kim; Curtis, Bonk J.; TingTing, Zeng. Surveying the Future of Workplace E-learning: The Rise of Blending, Interactivity, and Authentic Learning. eLearn, Issue 6, Vol. June 2005.

(7) McCullough, Colin; Aimard, Virginie. ELearning in Europe: How do trainers, teachers and learners rate e-learning? Cedefop, 2006. http://cms.eun.org/shared /data/pdf/report_survey_teachers_and learners_and_e-learning_final.pdf (8.2.2008.)

(8) OIZEOO: Organizacija informacija i znanja u elektroničkom obrazovnom okruženju (2002.-2005.). http://infoz. ffzg.hr/oizeoo/

(9) Omega http://omega.ffzg.hr/

(10)Quality and eLearning in Europe. Summary report. Bizmedia, 2002. http://www.elearningage.co.uk/docs/qua litysummary.pdf (12.2.2008.)

(11)Pawlowski, J.M. ISO/IEC 19796-1: How to Use the New Quality Standard for Learning, Education, and Training. Essen, 2006. http://cms.eun.org/shared/ data/pdf/iso19796-1_summary.pdf (10.2.2008.)

(12)Seljan, Sanja; Banek Zorica, Mihaela; Špiranec, Sonja; Lasić-Lazić, Jadranka. CALL (Computer-Assisted Language Learning) and Distance Learning. Proceedings of 29th International convention MIPRO. Rijeka, 2006. pp. 145-151

(13)Stephenson, John. Definitions of indicators of quality on the application of ICT to University Teaching. Tarragona, 2005. http://cms.eun.org/shared/data/pdf /qual_onlinehe.pdf (10.2.2008) 